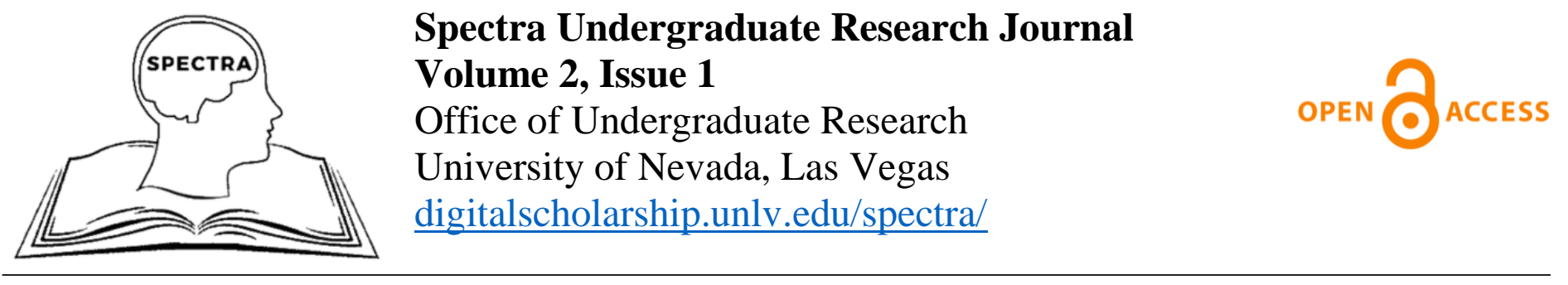

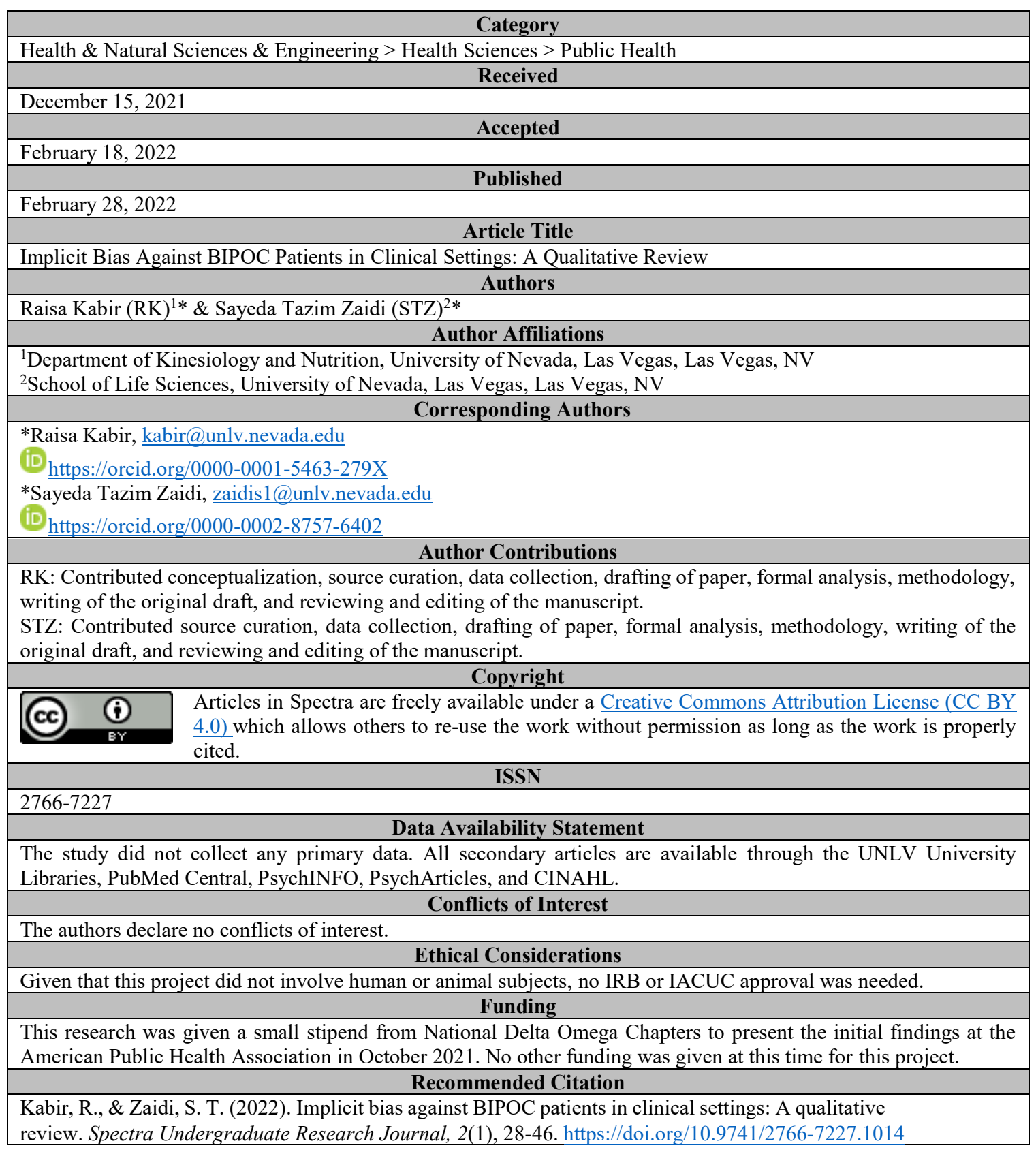




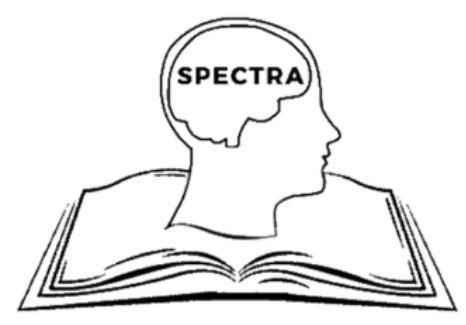

Spectra Undergraduate Research Journal

Volume 2, Issue 1

Office of Undergraduate Research

University of Nevada, Las Vegas

digitalscholarship.unlv.edu/spectra/

\title{
Implicit Bias Against BIPOC Patients in Clinical Settings: A Qualitative Review
}

Raisa Kabir $^{1} \&$ Sayeda Tazim Zaidi ${ }^{2}$

\section{Author Affiliations:}

${ }^{1}$ Department of Kinesiology and Nutrition, University of Nevada, Las Vegas, Las Vegas, NV, USA.

${ }^{2}$ School of Life Sciences, University of Nevada, Las Vegas, Las Vegas, NV, USA.

\begin{abstract}
Black, Indigenous, and People of Color (BIPOC) from stigmatized and marginalized communities face implicit bias in medicine. Implicit biases are unconscious attitudes and internalized discrimination developed through repeated practices based on stereotypes from a foundation of systematic racism. In clinical settings, it impacts individuals' healthcare experience and treatment outcomes. This study aimed to characterize and address implicit bias among healthcare providers toward BIPOC patients in clinical settings. A literature search in MEDLINE/PubMed, CINAHL, PsyArticles, PsycINFO from EBSCO databases was conducted to include all peer-reviewed studies (2012-2021) about implicit bias toward BIPOC. Most healthcare providers have some form of implicit bias-positive attitudes toward Whites and negative attitudes toward BIPOC which affects treatment decisions and overall quality of care they receive. BIPOC patients are likely to be prescribed a lower dosage of medication instead of opioid analgesics for both acute and chronic pain despite age, gender, or genetic factors. Structural and social factors that impact access to healthcare include the patient's sociodemographic variables such as age, gender, economic/employment stability, access to higher education, and geographic access to healthcare facilities. Future studies need to employ rigorous methods to examine the relationship between implicit bias and healthcare outcomes. Interventions targeting implicit attitudes among health care professionals are needed to reduce health disparities and improve the overall clinical care of BIPOC patients. Educational initiatives, reformed policies/practices, and new research are needed. Acknowledging racial/ethnic, and cultural bias in clinical settings minimizes implicit bias and reduces negative health care experiences for BIPOC.
\end{abstract}

Keywords: Implicit bias, racial bias, BIPOC patients, clinical, United States

Bias is prejudice against an individual or a group of people which stems from either negative or positive beliefs and ideologies. There are two different forms of biases: explicit and implicit bias. Implicit bias refers to unconscious attitudes and internalized discrimination based on common stereotypes that influence an individual's actions, judgments, decisions, and overall interactions (FitzGerald \& Hurst, 2017). It is a way of thinking/perception that continues to grow through repeated reinforcements done early in an individual's life or career. On the other hand, explicit bias occurs when an individual is fully aware of prejudice or negative attitudes toward certain groups (FitzGerald \& Hurst, 2017).

This study focuses on the implicit bias of healthcare providers toward Black, Indigenous, and People of Color (BIPOC). The phrase "People of Color" (POC) first appeared in the late 1700s in the Oxford English Dictionary and is commonly used in the US to refer to any race that is non-white (Oxford 
Learner's Dictionaries, n.d.; Garcia, 2020). The phrase categorizes Whites as one solid group while placing all other races including Anglo-Americans and European Americans in a single non-discriminatory group. This lack of specificity undermines the focus on individual issues faced by racially marginalized groups in the US. For this paper, instead of "POC", the term "BIPOC" was chosen to narrow down the target population and put an emphasis on racially marginalized groups including African American, Asian American, Hispanic and Latinx, Indigenous populations, and other marginalized racial/ethnic groups.

It has been reported that healthcare professionals have an unconscious bias towards BIPOC and other minority intersection groups in comparison to the general population (Williams et al., 2019). Negative implicit bias shapes a healthcare professional's overall behavior and course of treatment. These actions affect the quality of care, treatment plans, and patient perception in the healthcare system (Blair et al., 2013). Although physicians and other healthcare professionals vow to provide equal treatment for all their patients, unconscious biased thoughts impact an individual's thoughts and actions. In the U.S, implicit bias against BIPOC patients occurs not only due to the individual's ethnicity and race but also sociodemographic, socioeconomic, physiological, and psychological factors (Chapman et al., 2013). The 2015 US Department of Health and Human Services reports indicate racial and ethnic health disparities within different marginalized BIPOC communities (Centers for Disease Control and Prevention [CDC], 2019).

BIPOC patients from stigmatized and marginalized communities face implicit bias in medicine. They receive inadequate treatment for both acute and chronic pain in comparison to non-Hispanic White patients in Emergency, Recovery Room, and primary care settings (Mossey, 2011). Despite the pain intensity and regimen for pain control based on age, gender, and genetic influences, there is a substantial underreporting of pain from racial/ethnic minority patients (Mossey, 2011). The 2011 systematic review includes racial/ethnic disparities of pain studies from 1996 to 2011 (Mossey, 2011). The review reports BIPOC patients are 2 to 3 times less likely than White patients to be prescribed acute pain regimen including analgesia medications because physicians underrated pain scales for African American patients by greater than 2 points within an 11 point scale (Staton et al., 2007; Todd et al., 2000; Todd et al., 2007). Another cohort study $(\mathrm{n}=20,125)$ showed White or Hispanic White patients seen for abdominal or back pain between 2003 and 2007, over the age of 18, were 10\% more likely to be given an opioid regimen than BIPOC patients (Mills et al., 2010). Similar results were collected between 1993 to 2005, showing racial/ethnic minorities had lower rates of opioid analgesics regimens than White patients. Similarly, with chronic pain management, BIPOC patients are less likely to be given opioid analgesics or surgery referrals than White patients (Pletcher et al., 2008). Moreover, White patients were $2.67 \%$ more likely to be on an opioid analgesics' regimen than BIPOC patients (Chen et al., 2005). Additionally, studies report BIPOC cancer patients $(n=1300)$ were one-third as likely to receive World Health Organization recommended opioid analgesics treatment options than White patients at minority-serving outpatient clinics (Cleeland et al., 1994; Cleeland et al., 1997). BIPOC patients are likely to be prescribed NSAIDS, a lower dosage of medication instead of opioid analgesics (Staton et al., 2007; Todd et al., 2000; Todd et al., 2007). The review study by Mossey plays a crucial role in understanding how health care professionals comprehend patients' pain and shows evidence of inequality of pain quality and control regimen in BIPOC patients.

Implicit racial and ethnic biases are commonly measured using the Implicit Association Test (IAT). The IAT assessment indicates an individual's perception and association of different terms/attributes with one another. During the test, two different concepts appear where individuals will need to match pictures (some form of task) with an attribute (or words). For racial/ethnic IATs, the test will use consciously disavowed evaluation of the difference between a White or Black individual with words such as "good" or "bad" (Greenwald et al., 1998). A majority of studies included in this review utilize some form of IAT to assess participants' implicit biases. The purpose of this study was to characterize and address implicit bias among healthcare professionals in a clinical setting. 


\section{Methodology}

Literature Search and Inclusion Criteria: An extensive primary literature search was conducted in PubMed Central and PsychINFO, PsychARTICLE, and CINAHL in EBSCO database using the key terms: implicit bias, implicit association test, unconscious bias, clinical setting, medicine, and BIPOC (Black, Indigenous, People of Color). The search was repeated separately for each of the following racial minorities Asian Americans, Black, Hispanic and Latinx, and Indigenous. This was done to include all the studies that either targeted some or all minorities from the BIPOC population.

The PICO (Population, Intervention, Comparison, Outcome) framework was utilized to develop the literature question and search strategies and design the inclusion and exclusion criteria for the literature review (Richardson et al., 1995). The inclusion criteria were: (1) articles published in the past 10 years (2012 - 2021), (2) peer-reviewed articles, (3) articles published in the English language, (4) articles published in the United States, and (5) articles published on the implicit bias of patients in clinical and medical settings (Appendix B). The original search was conducted in May 2021 and revisited in October 2021 using customized key terms in selected search engines. A total of 25 literature results were located.

Exclusion Criteria: The exclusion criteria included gray literature, non-peer-reviewed articles, philosophical and opinion-based papers, and unavailability of the full text. Studies conducted outside of clinical settings, outside of the United States, not meeting the age group, or focusing on bias against physicians or nurse practitioners were also excluded.

Data Extraction and Synthesis: The Preferred Reporting Items for Systematic reviews and MetaAnalyses (PRISMA) guidelines (2021) were used for the data extraction process and reporting eligible studies that meet the inclusion criteria in Appendix A (Page et al., 2021). Eligibility screening was conducted independently by the two authors. From the initial search, the articles were retrieved based on the title and abstract. If the titles had key terms: implicit bias in healthcare, BIPOC, implicit bias, implicit association test, unconscious bias, clinical setting, medicine, and BIPOC or Asian Americans, Black, Hispanic and Latinx, and Indigenous, then the abstracts were reviewed. If the abstracts included implicit bias such as disability, ethnic/racial, gender, or socioeconomic class bias against BIPOC populations in the United States, then further screening was performed on the full text of the articles. During the full-text assessment, the studies that reported implicit bias only in clinical settings were included. Clinical settings include any medical facility such as dental clinics, emergency care, healthcare departments in academic settings, hospitals, nursing clinics, primary care, and various specialty clinics.

Two major databases, EBSCO and PubMed Central were utilized to identify research articles. Fifty-eight articles $(n=58)$ were excluded due to their repeated use in PubMed, PsychINFO, PsychARTICLE, and CINAHL. An addition of $(n=115)$ articles that were ineligible due to automation tools, and $(n=5)$ articles were excluded due to other reasons (Appendix A). After screening based on title and abstract, $(n=49)$ articles were included. Next, the full-text articles were retrieved and assessed for eligibility, and 25 studies met the inclusion criteria. Two investigators independently summarized the articles based on author, year of publication, study design, sample size, setting, target population, type of implicit bias, and the study outcome (Appendix B).

\section{Results}

Table 1 is the summary of the studies included. The studies were arranged alphabetically and assigned numbers. They were highly diverse in terms of study design, sample size, setting, target population, type of implicit bias, and outcomes. Four studies utilized qualitative methods such as brief questionnaires, structured or semi-structured interviews, and thematic analysis, 3 studies utilized clinical or case vignettes, 8 studies utilized quantitative methods such as betweensubjects randomized control trial, cohort study, crosssectional study, pilot study, and prospective study, 7 studies utilized telephone, web-based, selfadministered, or cross-sectional surveys, 3 studies utilized mixed methods (both qualitative and quantitative), and 5 studies conducted secondary data analysis. Out of these, 6 studies utilized IAT that was modified to fit the appropriate target population, for assessing implicit bias. Upon analyzing the included studies, implicit ethnic/racial bias was found to be the major type of implicit bias among all healthcare professionals who participated in the respective 
studies. Additionally, disability, gender, or socioeconomic class biases were found to be cooccurring with implicit ethnic/racial bias.

Implicit Ethnic/Racial Bias ( $\mathbf{n}=15)$ : Implicit ethnic bias in healthcare refers to an unconscious change in healthcare providers' behavior and clinical decisionmaking based on the patient's ethnicity or race (Blair et al., 2013). Blair et al. (2013) administered a telephone survey and performed 2 IATs to measure clinicians' implicit attitudes towards Black and Latino patients and how it affects these patients' perception of care. The sample size included 210 primary care providers (PCP) - 54\% female and 75\% White, and 6129 patients - Black, Latino, or White, diagnosed with hypertension. IAT scores indicated that $43 \%$ of clinicians had a moderate or strong implicit bias against Blacks, and $51 \%$ had a moderate or strong implicit bias against Latinos. Additionally, compared to White patients, Black patients gave equivalent ratings to their PCPs for patient-centeredness while Latino patients gave comparatively lower ratings. Further analysis indicated that the higher the clinician's implicit bias, the lower their ratings by Black patients suggesting that implicit bias may negatively affect clinician-patient relationships and care process. Another study by Blair et al. (2014) utilized IAT to determine the relationship between clinicians' implicit ethnic or racial bias and hypertension treatment outcome among Black and Latino patients compared to White patients. The sample size included 138 primary care clinicians (PCC) - 54\% female, and 83\% White, and 4794 patients - Black, Latino, or White, diagnosed with hypertension. The results indicated that approximately $70 \%$ of the clinicians had an implicit bias against Blacks and Latinos - $42 \%$ had a moderateto-strong implicit bias against Blacks and $51 \%$ had a moderate-to-strong implicit bias against Latinos.

Pearl \& Percec (2019) utilized a 9-item Everyday Discrimination Scale to explore the prevalence of age-based discrimination among patients undergoing cosmetic procedures in various settings. The sample size included 50 patients including White, Black or African American, American Indian or Alaska Native, Hispanic and/or Latino/a, and Multiracial patients. The results indicated that $16 \%$ of the participants endorsed age-based discrimination in the healthcare setting and reported receiving inappropriate comments from doctors due to age.
Additionally, these participants also reported to have significantly poorer self-rated health, lower selfesteem, and greater anticipation of age discrimination compared to those who did not face age-based discrimination.

\section{Implicit Ethnic/Racial Bias affecting pain} management regimen (n=6): Racial disparities are continued to be seen in different stages of an individual's health care visits, especially for BIPOC patients seeking pain management. For instance, Badreldin et al. (2019) conducted a retrospective cohort study of women's postpartum pain scores, opioid administration, and overall discharge prescriptions. Study included $(n=9,900)$ women $68.4 \%$ non-Hispanic White, $21 \%$ Hispanic, and $10.6 \%$ non-Hispanic Black individuals. The results indicated that non-Hispanic White women were less likely to report pain scores greater than 5 yet received a significantly greater dosage of pain medications than Hispanic and non-Hispanic Black women. Data indicated that non-Hispanic White women were more likely to receive an opioid prescription by almost $46 * \%$ higher than Hispanic and non-Hispanic Black women during discharge from the clinic. This study concludes that the lack of pain management administered for Hispanic and non-Hispanic black women cannot be explained through less perceived pain during postpartum.

Pain perception plays hand in hand with management patterns and medication administration. Edmonds et al. (2017) conducted a self-administered survey in which they utilized a case vignette to explore healthcare providers' racial bias against pregnant Black females seeking pain management compared to White females. The sample size included 76 obstetrician-gynecologists $-67.5 \%$ females, and $68.8 \%$ White, and 1 nurse practitioner. The statistical data of opioid prescription or performing urine tests concerning demographic characteristics suggested that factors such as the location of practice, affiliation with politics, and supervision of residents were associated with an opioid prescription. The survey results demonstrated that physicians' suspicions and their referral behavior were correlated to the patient's race. Fetal harm was the top concern followed by opioid abuse in Black patients while the primary concern in White patients was opioid abuse. 
For individuals who suffer from cancer, pain perception is a key component in ensuring the overall health of the patient. Fisch et al. (2012) collected data from patients with breast, lung, prostate, or colorectal cancer who were mostly women $(71 \%)$ and white $(86 \%)$. The study indicated there were higher odds of inadequate analgesia prescribing in minority patients twice as much as non-Hispanic White patients. Clinicians are concerned about addiction and adverse effects when prescribing pain management medications to minority patients. There is a significant low mutual trust and worse quality of care present when treating minority patients between non-Hispanic White patients and Hispanic patients.

False beliefs based on biological differences between BIPOC and White patients also influence the treatment recommendations and pain perception of BIPOC patients. For instance, Hoffman et al. (2016) conducted a study on associated beliefs on the racial bias of pain management between Black and White patients. The study was divided into 2 parts where the first study demonstrates common racial beliefs of White adults without medical training and the second study discusses beliefs of medical students and residents based on their years of training. The second study incorporated racial bias in pain perception and racial bias in treatment recommendations. The results indicated that White medical students and residents have common racial beliefs on biological differences between Black patients and white patients. Many believe that Black patients would feel less pain in comparison to White patients which may account for the differences in pain management prescription between the two races.

Racial stigma impacts the type of pain medications and level of care BIPOC patients receive from their physicians. Hirsh et al. (2019) utilized randomized control trials to study the perceived physician implicit bias on chronic pain of Black patients and the effectiveness of the interventions to reduce the bias. The study included a sample size of 436 patients across the U.S. and separated into 2 sessions. The sessions requested physician providers to input their clinical experiences with pain on a visual analog scale. Session 1 results indicated that $50 \%$ of the sample size, the majority being White physicians, showed implicit bias ideologies for pain care management treatments (opioids, pain specialists, or physical therapy) for Black patients. The preliminary results of this study provided insight on physician implicit bias on pain care while the final results showed a costive chance to previous biased beliefs.

Provider implicit bias is harmful in clinical decision-making as most BIPOC patients receive poor treatment and pain care. Oliver et. al (2014) explores osteoarthritis pain management in African American patients and the lack of Total Knee Replacement (TKR) as a treatment option. Older African Americans are more likely to be diagnosed with osteoarthritis than White patients, yet they are not offered TKR as a form of treatment in comparison to half of the white patients. These results further indicate the role of racial bias in pain management and treatment options.

\section{Implicit Ethnic/Racial Bias affecting patient-} physician interaction (n=3): Overall patient-physician interaction is also heavily influenced by perceived implicit bias from physicians and perceived patient racial discrimination. Cooper et al. (2012) conducted a cross-sectional study with 40 primary care clinicians and 296 patients within an urban community-based practice. The study indicated white patients had a better interaction and a higher rating of interpersonal care between the patient and primary care clinicians. However, with BIPOC patients, there were much more negative results based on lower patient positive effects and poor overall interpersonal care. For instance, Racial bias played a large role in interpersonal care; for instance, black patients had lower predicted probabilities of perceiving respect from the health care provider by almost (15\% lower) than their counterparts. The study indicated Black patients had almost a $20 \%$ longer medical visit and a much smaller pace of dialogue with their clinician while White patients had a $21 \%$ slower visitation with fast-paced dialogue and $25 \%$ less clinician dominant conversations. White patients had a higher overall positive effect with their physicians as they had more white patient visitations and patient-centered conversations. White patients were more likely to recommend the clinician to peers by $20 \%$. Overall, white patients reported reliving more respect from their clinician and had positive overall interaction.

Eliacin et al. (2020) studied the impacts of perceived racial bias on veterans' engagement behaviors and healthcare communication. The authors interviewed 85 African-American veterans who were 
receiving services for mental health from the US Department of Veterans Affairs (VA) regarding their views on racial discrimination experiences in healthcare. The result suggested that many veterans felt that there was a lack of racial diversity and perception amongst the providers regarding fear of Black patients. Thus, these experiences of veterans during clinical encounters developed a fear within the Black veterans about being negatively judged based on perceived stereotypes.

Hagiwara et al. (2017) utilized an analysis on self-reported and video recorded data from 112 Black patients from low income and 14 non-Black physicians at a primary care in the U.S. The results indicated that physician implicit bias is positively correlated with patient-physical interactions. Physicians with implicit bias talked significantly more than the patients, while physicians with lower implicit bias had a longer interaction with patients. Additionally, patients who had faced previous discrimination and bias were reported to have a long time talking in comparison to the physician but still had an overall short patientphysician interaction time. The results of this study further depict the lack of trust BIPOC patients have in their physicians due to implicit bias.

Implicit Ethnic/Racial Bias affecting access to healthcare $(\boldsymbol{n}=3)$ : Armstrong et al. (2013) conducted a randomized survey including both African American and White adults living in the U.S. incorporating health care system distrust scale, the experience of dissemination scale, access to care, and sociodemographic factors. African American individuals reported a greater barrier when accessing health care. They reported a higher lack of health insurance, lack of a personal physician, are unable to pay for care, and are likely to be contacted by collections for medical bills. Among the African American group collected, almost $80 \%$ reported one incident of racial domination compared to white patients. The study also indicated almost $60 \%$ of African Americans reported 3 or more settings than white patients. African Americans also had a much higher level of distrust in healthcare.

Individuals with serious mental health issues and people of color (POC) in the criminal legal system face dual disproportionality. Hedden et al. (2021) screened 623 individuals for mental health issues from 8 midwestern jails in 2017. The results suggested that, although there was no racial discrimination found in jail-based treatment, POC faced discrimination when it came to receive community-based mental health and substance use treatment. Additionally, POC had 4.5 times greater odds of receiving co-occurring disorder treatment and 1.9 greater odds of receiving community-based mental health treatment compared to White individuals in jail.

Ross et al. (2020) utilized data from the National Hospital Ambulatory Medical Care Survey Emergency Department to explore the impact of racial bias on the use of diagnostic imaging among nonWhite patients. The results indicated that non-White patients had significantly lower rates of receiving diagnostic imaging (41\%) during visits to the emergency department (ED) compared to White patients $(49 \%)$. Further statistical analysis indicated that demographic factors such as age, and gender, and socio-economic factors such as insurance status, and hospital setting, and location significantly influence the use of diagnostic imaging.

Implicit Racial with Disability Bias $(n=3)$ : Implicit disability bias occurs in healthcare when healthcare providers interact and treat disabled patients differently than non-disabled patients due to negative disability attitudes (VanPuymbrouck et al., 2020). Hausmann et al. (2015) conducted a pilot study by utilizing a crosssectional survey of Black individuals with spinal cord injury (SCI) to assess is implicit racial bias amongst SCI physicians when it comes to functioning and wellbeing of Black patients suffering from SCI. The sample size obtained for the experiment was 162 patients with SCI and their 14 SCI physicians. Statistical analysis on data collected indicated that physicians unconsciously associated positive ideation towards individuals with White faces and negative concepts with African American faces. Physicians had strong pro-white bias and anti-black bias which was even greater with SCI patients who had associated disability and poor psychosocial health outcomes.

VanPuymbrouck et al. (2020) performed a secondary analysis on Disability Attitudes - Implicit Association Test (DA-IAT) to explore health care providers' implicit attitudes toward patients with disabilities. The sample size included 25,006 health care providers from diverse medical fields occupational and physical therapy assistants, nursing and home health assistants, and diagnosis and treating 
practitioners including $\mathrm{MD}$ and dentists. Of the participants, $74.9 \%$ were White and $80.6 \%$ were females. The results indicated that $83.6 \%$ of healthcare providers implicitly preferred non-disabled patients. The participants' average score on DA-IAT was 0.54 indicating that they had a moderate implicit bias against disabled patients.

A previous study by VanPuymbrouck \& Friedman (2019) aimed to understand occupational therapy students' perspectives on disabled patients by utilizing DA-IAT. The sample size included 67 occupational therapy students - 89.6\% Female, $83.6 \%$ White, and $97.0 \%$ non-disabled. The DA-IAT scores indicated that $31.3 \%$ and $35.8 \%$ of the participants had moderate and strong preferences for non-disabled patients. Further thematic analysis indicated that the participants had pre-established beliefs of disability as individualized and an undesirable characteristic and recognized as a significant part of a person's identity like gender or ethnicity.

Implicit Racial with Gender Bias (n=2): Implicit gender bias occurs when healthcare providers assign different treatments based on gender due to the belief that females are physically weaker than males and cannot undergo certain invasive treatments (Daugherty et al., 2017). Daugherty et al. (2017) utilized IAT and randomized clinical vignettes to assess implicit gender bias among cardiologists and how it affects their decision to perform cardiovascular tests among BIPOC patients. The sample size included 503 cardiologists $87 \%$ male, and $62 \%$ White. The results indicated that $74.7 \%$ and $89.9 \%$ of the cardiologists had some implicit gender bias on risk-taking and strength. Additionally, cardiologists with gender bias believed that angiography for coronary artery disease (CAD) is more useful for male patients than female patients. Further analysis indicated that female cardiologists had less implicit gender bias compared to males.

Breathett et al. (2020) utilized clinical vignettes to determine whether racial and gender bias affects the allocation of advanced heart failure therapies for African American (AA) patients. The sample size included 46 U.S.-based members of an international heart transplant organization - 52\% women, $43 \%$ racial minority. The results indicated that AA was perceived as sicker than other racial groups, and AA women received less prior care compared to White women. The participants also critiqued female patients' appearances more harshly than male patients. Additionally, having children was seen as a liability, and family dynamics and financial status were seen as a concern for AA women. Females were also perceived to receive less social support than males.

Implicit Racial with Socioeconomic Class Bias (n=4): Implicit social status and socioeconomic class stereotypes impact the type of quality care and treatment options available for patients. Social class is often very interconnected within the BIPOC community, as many BIPOC patients reside in poor neighborhoods, have lower salaries, lack healthcare, and overall have lack of access to urgent treatment (Freeman et al., 2017). According to Freeman et al., (2017), there are reported worse health outcomes with BIPOC patients than white patients with HIV. The data collected included responses from $78.38 \%$ African American, 21.62\% Latino/Hispanic, and overall $97.30 \%$ lower socioeconomic status patients. The study identified four major themes of implicit bias and socioeconomic for BIPOC patients which include: social segregation, concentrated poverty, minimal resources, and attitudes towards healthcare.

Campesino et al. (2012) studied a group of Spanish-speaking Latina women, English-speaking Latina women, and African American women receiving cancer treatments in Arizona. The results indicated that almost $46 \%$ of the participants believed that their quality of care was influenced by their race and language. Additionally, $77 \%$ of Latina and African women believed that there is bias against minorities. However, these patients expressed they initially experienced bias at their PCP towards the beginning stages of their disease. Spanish-speaking Latina patients believed that there is a difference in their care due to the language barrier, undocumented status, and poor healthcare insurance. While English-speaking Latina patients indicated discrimination due to skin color, undocumented status, poor health insurance, and language barrier. Similarly, African American women believed that their level of care was affected by stereotypes and discrimination related to lack of insurance, skin color, race, gender, and healthcare resources (Campesino et al., 2012). Overall, all three demographic groups of patients indicated healthcare discrimination due to their race and lack of insurance.

According to Haider et al., (2015), healthcare professionals have reported less MRI for patients from 
lower socioeconomic status than individuals from higher social class (Haider et al., 2015). MRI is an expensive imaging technique that most uninsured patients can receive service off unless the injury is urgent and traumatic. Additionally, the study indicated implicit bias within primary care physicians for outpatient clinics in comparison to surgeons, who assess patients when injury/disease has gotten far worse. There is a correlation between the decreased level of care and minimally available healthcare services with a patient's socioeconomic class.

Nguyen et al. (2013) utilized data from Nationwide Inpatient Sample to analyze racial disparities in mortality in obese non-Hispanic Black patients undergoing Bariatric surgery compared to non-Hispanic White patients. The sample size included 115,507 bariatric surgeries between 1999 to 2007. The results indicated that non-Hispanic Blacks had lower household incomes compared to non-Hispanic Whites. Additionally, non-Hispanic Black patients were less likely to have private insurance and a significant number of them had Medicare or Medicaid insurance. Further analysis indicated that non-Hispanic Black patients were more likely to be treated in teaching hospitals with lower surgical volumes and less experienced physicians. They had a $73 \%$ increased risk of perioperative mortality and significantly higher inhospital mortality rates compared to non-Hispanic White.

\section{Discussion}

Results of this paper suggest that implicit bias against BIPOC patients is present among healthcare professionals despite their level of experience and specialties. This review study identified racial bias as the significant type of implicit bias in healthcare against BIPOC patients. The studies included in this review indicated three additional types of implicit biases that coincide with racial bias in various combinations - disability bias, gender bias, and socioeconomic class bias.

All studies reported implicit racial/ethnic bias against BIPOC patients in diverse healthcare settings. Racial bias plays a significant role in overall implicit bias. It affects the patient-provider interaction, length of visitation, conversation dominance, appointment resists, clinical decisions, and medical dosage. One study indicated a higher clinician bias which in turn negatively impacts the overall experience of the black patients (Blair et al., 2013). Another study found that $70 \%$ of the participating clinicians had indicated implicit bias against Black and Hispanic patients (Blair et al., 2014).

One study reported age-based discrimination in BIPOC patients undergoing cosmetic procedures (Pearl \& Perec, 2019). The ageist comments or jokes by the providers rooting from systematic racism negatively affect the patient-provider relationship, selfesteem, and overall healthcare experience of BIPOC patients, particularly women. Age bias could also work the other way round. For example, PCP focuses on older patients more than younger patients (Blair et al., 2013). This implicit behavior could result in overdiagnoses of complex health issues that are rather agerelated. In the upcoming years, the number of older American adults is expected to rise exponentially and by 2030, 1 in 5 Americans would be 65 years and older (U.S. Census Bureau, 2021). Thus, there is an urgent need to address implicit age bias in healthcare.

Three studies reported providers' implicit bias against BIPOC patients with disabilities (VanPuymbrouck et al. 2020; VanPuymbrouck \& Friedman 2019). The Americans with Disabilities Act (ADA) of 1990 prohibits discrimination against the disabled in healthcare (American Disabilities Act, 2021). A recent study has revealed that a significantly high number of physicians throughout the U.S. believe that patients with disabilities have worse quality of life than nondisabled patients (Iezzoni et al., 2021). A majority of physicians are not confident in their ability to provide quality care to disabled patients compared to non-disabled patients (Iezzoni et al., 2021). The root cause of disability bias in healthcare is the preestablished belief that disability prevents individuals from having a quality life due to dependency and inability to carry out normal functions. Older BIPOC patients, in particular, are at a higher risk of facing the negative consequences of providers' implicit disability attitudes as they historically have higher disability rates compared to older White patients (CDC, 2019).

Two studies reported providers' implicit gender bias against BIPOC women. According to the Association of American Medical Colleges Council on Ethical and Judicial Affairs, gender bias plays a significant role in providers' treatment decisionmaking (AAMCC). Gender discrimination against 
BIPOC women is prominent and affects their medical diagnosis especially the receiving of advanced heart therapy, cardiovascular tests such as angiography, and pain management during pregnancy (Daugherty et al., 2017; Breathett et al., 2020). This discrimination is a serious concern that needs to be addressed in the medical field as improper diagnoses of such serious conditions could lead to mortality.

Four studies reported providers' implicit socioeconomic class bias against BIPOC patients. Socioeconomic factors such as insurance status, income, employment status, and education level play a significant role in treatment options within the hybrid system of U.S. health care. Social-economic classes are intertwined with the BIPOC minority community. Most BIPOC patients often live in poor neighborhoods with minimal salaries and a lack of access to healthcare (Freeman, 2017). Racial minorities from lower socioeconomic states suffer from both chronic and acute diseases. For instance, patients from racially marginalized groups suffer from combined medical problems such as obesity, hypertension, diabetes, and heart diseases due to a lack of proper care within the correct time frame (Nguyen, 2013). Non-Hispanic Black patients receiving bariatric surgeries suffer from higher racial and socioeconomic disparities than nonHispanic white patients (Nguyen, 2013). Socioeconomic classes also reveal the type of care an individual receives. For instance, a study indicated most non-Hispanic Black patients are likely to be treated at teaching hospitals where there is much less surgical volume and surgeons with much less experience (Nguyen, 2013). Obese non-Hispanic Black females reported delayed referrals for surgeries and difficulty obtaining insurance funding when preparing for bariatric surgery (Nguyen, 2013).

Interactions between patients and providers: According to IAT scores, there is a pro-White bias among healthcare providers. IAT race scores were significantly higher in healthcare professionals who considered themselves politically conservative or identified as White. Similar studies indicated that healthcare professionals believed their White patients were more cooperative than Black patients preferring fueling the pro-White/anti-Black bias (Cooper et al., 2012). One study indicated that healthcare professionals believed their White patients were more cooperative than Black patients fueling the pro-
White/anti-Black bias (Cooper et al., 2012). Another study indicated that physicians with pro-White bias had fewer interactions with their BIPOC patients (Hagiwara et al., 2017). The 2012 study reported that Black patients had 20\% longer medical visits with slower-paced dialogue and more clinician-dominant conversation than White patients (Cooper et al., 2012).

Few studies indicated a lower patient-provider interaction which was more significant in Black and Hispanic patients in comparison to White patients (Blair et al., 2013; Blair et al., 2014). It has been shown that smaller patient-to-physician time leads to hesitancy to visit their physician regularly and openly discuss health concerns (Hagiwara et al., 2017). These results highlight the need for racially concordant care to reduce racial disparities in the U.S. healthcare system. A 2019 study found that Black patients are more likely to receive preventative care screening if their physician is also a Black individual (Marcella et al., 2019). This study indicates that racially-concordant care improves patient-provider interaction and allows for better overall healthcare outcomes for Black patients.

\section{Medical Treatment and Pain Management}

Decisions: Nearly all studies included in this review reported or suggested that implicit bias of healthcare providers affected their medical and treatment decisions. The 2020 study indicated that non-White patients are also less likely to receive diagnostic imagining during ER visits by almost $41 \%$ (Ross, 2020). Implicit bias also affects pain management regimens. Pain perception is a complex phenomenon that is different for each individual. Racial bias has influenced the beliefs on pain perception in individuals in both non-medical and medical settings. Racial bias in pain perception is correlated to racial bias in treatment administration. Many individuals believe that Black patients are less likely to feel pain compared to White patients (Hoffman et al., 2016). This is crucial because it determines the level of care an individual receives upon examination. For instance, one study recorded higher odds of inadequate analgesia prescribing in pregnant BIPOC women than nonHispanic White patients, although White patients are less likely to report pain (Fisch et al., 2012). When prescribing pain medication to BIPOC patients, clinicians focus on external factors such as addiction 
and adverse effects (Fisch et al., 2012). White patients are more likely to receive opioid treatments, pain specialists, and overall physical therapy than Black patients for pain management (Hirsh et al., 2019). Pain perception can also impact long-term treatments such as surgery options. Older African American individuals are more likely to suffer from osteoarthritis, yet they are less likely to be offered the Total Knee replacement (Oliver et al., 2014). Providers who had no connections to disabled people were more likely to be prejudiced and highly preferred nondisabled patients (VanPuymbrouck \& Friedman, 2019). Overall pain medication dosage and prescription are negatively impacted by racial-based implicit bias. When administering or prescribing for Black patients, clinicians are more likely to question the ulterior motives of the patients (Edmonds et al., 2017). Due to these racial disparities, BIPOC patients receive inadequate proper treatment or medication regimens for acute and chronic pain.

Deconstructing systematic racism: Systematic racism in medicine stems from multiple different origins and has multiple different levels based on institutional, interpersonal, and internal levels and ideologies (Madara, 2021). There are many different layers in deconstructing overall systematic racism. The first steps include addressing the initial issue. In mid-2008, American Medical Association (AMA) concluded an extensive three-year study on the racial gap within medicine (Madara, 2021). Following the study, AMA released an official apology regarding common systematic racism and overall implicit bias within medicine. This was the first official initiative taken by AMA and since then, they have equity plans to continue to deconstruct previously embedded systematic racism to advance both racial and social justice. The 2021 to 2023 AMA equity plan is a 3-year plan which incorporates five strategic approaches: Embed equity, build alliances and share power, ensure equity in innovation, push upstream, and lastly, foster truth and reconciliation (Madara, 2021). These are just some of the few actions being taken to slowly deconstruct common institutionalized, interpersonal, and internal levels of bias and racism within medicine.

\section{Importance to the Field}

There is limited research on implicit bias against BIPOC individuals within healthcare and medical settings. This study is crucial to public health and medical sciences as it opens up discussion on common stereotypes about BIPOC patients and hopes to create more dialogue about these issues that can affect an individual's level of care. It is also crucial as it shows how little data is available for the public on this topic from the last ten years on implicit bias among BIPOC patients.

\section{Implications for Future Research and Future Direction}

Future studies should collect data on a more diverse population of patients and physicians to understand the patient's perspective, physician-patient interactions and evaluate overall care. They should also incorporate Indigenous/Native American populations to minimize the gap in the literature. Future studies should include older data ranging from early 2000 to get a better understanding of the effect of implicit bias among BIPOC patients. This would also give the researchers an idea if there are any successful intervention programs and policies that have helped minimize implicit bias within medical settings. Since most studies included in this review focus on shortterm treatment outcomes, future research could incorporate longitudinal studies to assess the impact of implicit bias on long-term outcomes. Additionally, incorporating population-based studies and randomized control trials would help to generalize the results to a broader BIPOC population in the US. A better understanding of the negative impact of implicit bias and common stereotypes will increase new initiatives and policies on a systematic level within different communities. There is a need to start a dialogue on this topic as it affects an individual's overall healthcare and physician experience. This paper can be used as a foundation for clinical-based research focusing on implicit bias in US health care.

\section{Limitations of the Included Studies}

Although most of the studies did an excellent job in collecting data on implicit bias, this is still a sensitive topic. Due to that, there could have been nonresponse bias and response bias. Additionally, data from midwestern and southeastern states would be interesting for this study. Comparing the provider/healthcare worker bias between liberal and conservative views would give the confounding 
variables to this study. Some studies have a low percentage of BIPOC patients in their sample sizes. Additionally, most studies mainly focused on implicit bias against African American and Latino/Hispanic patients. More studies are needed to incorporate other non-White ethnic minorities such as Asian Americans and Native Americans in the sample sizes. Additionally, the results are specific to the participants of these studies and cannot be generalized to all BIPOC populations in the US.

\section{Limitation of the Review}

There are some limitations within this paper. There was limited data available from 2012 to 2021 that fit the inclusion criteria. This review looked at articles only from CINAHL, PubMed Central/MEDLINE, PsycINFO, and PsycArticles. There was a lot of gray literature that was excluded from the result data collection. Although the term "BIPOC" was used to locate studies for marginalized racial/ethnic patients, there was very little research for Asian American patients and no recent studies on Indigenous patients. Additionally, this paper only focused on implicit bias in BIPOC patients in the United States. It would be interesting to look into studies from different parts of the world and published in various languages. Also, disability, gender, and socioeconomic class biases were not included in the search terms but rather found to be coinciding with implicit racial/ethnic bias in the results of this review. Furthermore, this review found only one study that addresses how implicit age bias of physicians affects the overall healthcare experience of BIPOC patients seeking cosmetic procedures. Thus, there is a need to address the effects of implicit age bias on treatment outcomes in BIPOC patients across diverse healthcare settings.

\section{Conclusions}

The evidence within this review shows that implicit bias attitudes and beliefs towards BIPOC individuals are shared among the general population and healthcare professionals. The results from this study indicated the negative outcomes and influences of provider bias on BIPOC patients. Providers report preferring pro-White patients over BIPOC patients which are very damaging for the patient-provider communication. This study indicates that BIPOC patients are less likely to seek preventative treatment and openly discuss their symptoms or diseases. The study also found that implicit bias in healthcare can impact an individual's quality and level of care, and type of treatment. To start a change in implicit bias, there need to be policies, workshops, and new ways of learning set in motion on a systematic level. Additionally, hiring more BIPOC doctors or healthcare professionals will greatly increase patient-provider relationships.

\section{Acknowledgments}

We would like to express our sincere gratitude and appreciation to our faculty advisor, Dr. Manoj Sharma, for his continuous motivations, patience, and guidance throughout this research.

\section{References}

American Disabilities Act. (2021, December 1). What is the Americans with Disabilities Act (ADA)? ADA National Network. Retrieved December 5, 2021, from https://adata.org/learn-about-ada American Medical Association. (n.d.) The AMA's strategic plan to embed racial justice and advance health equity. Retrieved October 1, 2021, from https://www.amaassn.org/about/leadership/ama-s-strategicplan-embed-racial-justice-and-advance-healthequity

Armstrong, K., Putt, M., Halbert, C. H., Grande, D., Schwartz, J. S., Liao, K., Marcus, N., Demeter, M. B., \& Shea, J. A. (2013). Prior experiences of racial discrimination and racial differences in health care system distrust. Medical Care, 51(2),

144-150. https://doi.org/10.1097/MLR.0b013e31827310 a1

Badreldin, N., Grobman, W. A., \& Yee, L. M. (2019). Racial disparities in postpartum pain management. Obstetrics and Gynecology, 134(6), 1147-1153. https://doi.org/10.1097/AOG.0000000000003 561

Blair, I. V., Steiner, J. F., Fairclough, D. L., Hanratty, R., Price, D. W., Hirsh, H. K., Wright, L. A., Bronsert, M., Karimkhani, E., Magid, D. J., \& Havranek, E. P. (2013). Clinicians' implicit ethnic/racial bias and perceptions of care 
among Black and Latino patients. Annals of Family Medicine, 11(1), 43-52. https://doi.org/10.1370/afm.1442

Blair, I.V., Steiner, J. F., Hanratty, R., Price, D. W., Fairclough, D. L., Daugherty, S. L., Bronsert, M., Magid, D. J., \& Havranek, E. P. (2014). An investigation of associations between clinicians' ethnic or racial bias and hypertension treatment, medication adherence and blood pressure control. Journal of General Internal Medicine: JGIM, 29(7), 987-995. https://doi.org/10.1007/s11606-014-2795-z

Breathett, K., Yee, E., Pool, N., Hebdon, M., Crist, J. D., Yee, R. H., Knapp, S. M., Solola, S., Luy, L., Herrera-Theut, K., Zabala, L., Stone, J., McEwen, M. M., Calhoun, E., \& Sweitzer, N. K. (2020). Association of gender and race With allocation of advanced heart failure therapies. JAMA Network Open, 3(7), 1-14. https://doi.org/10.1001/jamanetworkopen.202 0.11044

Centers for Disease Control and Prevention (CDC). (2019, October 25). Infographic: Adults with Disabilities: Ethnicity and Race | CDC. Retrieved October 1, 2021, from https://www.cdc.gov/ncbddd/disabilityandheal th/materials/infographic-disabilities-ethnicityrace.html

Campesino, M., Saenz, D. S., Choi, M., \& Krouse, R. S. (2012). Perceived discrimination and ethnic identity among breast cancer survivors. Oncology Nursing Forum, 39(2), E91-E100. https://doi.org/10.1188/12.ONF.E91-E100

Chapman, E. N., Kaatz, A., \& Carnes, M. (2013). Physicians and implicit bias: how doctors may unwittingly perpetuate health care disparities. Journal of General Internal Medicine, 28(11), 1504-1510. https://doi.org/10.1007/s11606013-2441-1

Chen, I., Kurz, J., Pasanen, M., Faselis, C., Panda, M., Staton, L. J., O’Rorke, J., Menon, M., Genao, I., Wood, J., Mechaber, A. J., Rosenberg, E., Carey, T., Calleson, D., \& Cykert, S. (2005). Racial differences in opioid use for chronic nonmalignant pain. J Gen Intern Med, 20(7). https://doi.org/10.1111/j.1525-

1497.2005.0106.x
Cleeland, C. S., Gonin, R., Basz, L., Loehrer, P., Pandya, \& K. J. (1997). Pain and treatment of pain in minority patients with cancer. The Eastern Cooperative Oncology Group Minority Outpatient Pain Study. Ann Intern Med, 127(9), 813-816. https://doi.org/10.7326/0003-4819127-9-199711010-00006

Cleeland, C. S., Gonin, R., Hatfield, A. K., Edmonson, J. H., Blum, R. H., Stewart, J. A., \& Pandya, K. J. (1994) Pain and its treatment in outpatients with metastatic cancer. The New England Journal of Medicine, 330, 592-596. https://doi.org/10.1056/NEJM1994030333009 02

Cooper, L. A., Roter, D. L., Carson, K. A., Beach, M. C., Sabin, J. A., Greenwald, A. G., \& Inui, T. S. (2012). The associations of clinicians' implicit attitudes about race with medical visit communication and patient ratings of interpersonal care. American Journal of Public Health, 102(5), 979-987. https://doi.org/10.2105/AJPH.2011.300558

Daugherty, S. L., Blair, I. V., Havranek, E. P., Furniss, A., Dickinson, L. M., Karimkhani, E., Main, D. S., \& Masoudi, F. A. (2017). Implicit gender bias and the use of cardiovascular tests among cardiologists. Journal of the American Heart Association, $6(12)$. https://doi.org/10.1161/JAHA.117.006872

Edmonds, B. T., McKenzie, F., Austgen, M. B., Ashburn-Nardo, L., Matthias, M. S., \& Hirsh, A. T. (2017). Obstetrical providers' management of chronic pain in pregnancy: A vignette study. Pain Medicine, 18(5), 832-841. https://doi.org/10.1093/pm/pnw195

Eliacin, J., Matthias, M. S., Cunningham, B., \& Burgess, D. J. (2020). Veterans' perceptions of racial bias in VA mental healthcare and their impacts on patient engagement and patientprovider communication. Patient education and counseling, 103(9), 1798-1804. https://doi.org/10.1016/j.pec.2020.03.017

Fisch, M. J., Lee, J. W., Weiss, M., Wagner, L. I., Chang, V. T., Cella, D., Manola, J. B., Minasian, L. M., McCaskill-Stevens, W., Mendoza, T. R., \& Cleeland, C. S. (2012). Prospective, observational study of pain and analgesic prescribing in medical oncology 
outpatients with breast, colorectal, lung, or prostate cancer. Journal of Clinical Oncology : Official Journal of the American Society of Clinical Oncology, 30(16), 1980-1988. https://doi.org/10.1200/JCO.2011.39.2381

FitzGerald, C., \& Hurst, S. (2017). Implicit bias in healthcare professionals: A systematic review. BMC Medical Rthics, 18(1), 19. https://doi.org/10.1186/s12910-017-0179-8

Freeman, R., Gwadz, M. V., Silverman, E., Kutnick, A., Leonard, N. R., Ritchie, A. S., Reed, J., \& Martinez, B. Y. (2017). Critical race theory as a tool for understanding poor engagement along the HIV care continuum among African American/Black and Hispanic persons living with HIV in the United States: A qualitative exploration. International Journal for Equity in Health, 16(1), Article 54. https://doi.org/10.1186/s12939-017-0549-3

Garcia, S. E. (2020, June 17). BIPOC: What does it mean? The New York Times. Retrieved December 10, 2021, from https://www.nytimes.com/article/what-isbipoc.html

Greenwald, A. G., McGhee, D. E., \& Schwartz, J. L. (1998). Measuring individual differences in implicit cognition: The implicit association test. Journal of Personality and Social Psychology, 74(6), 1464-1480. https://doi.org/10.1037//0022-3514.74.6.1464

Haider, A. H., Schneider, E. B., Sriram, N., Dossick, D. S., Scott, V. K., Swoboda, S. M., Losonczy, L., Haut, E. R., Efron, D. T., Pronovost, P. J., Lipsett, P. A., Cornwell, E. E., 3rd, MacKenzie, E. J., Cooper, L. A., \& Freischlag, J. A. (2015). Unconscious race and social class bias among acute care surgical clinicians and clinical treatment decisions. JAMA Surgery, 150(5), 457-464.

https://doi.org/10.1001/jamasurg.2014.4038

Hagiwara, N., Slatcher, R. B., Eggly, S., \& Penner, L. A. (2017). Physician racial bias and word use during racially discordant medical interactions. Health Communication, 32(4), 401-408. https://doi.org/10.1080/10410236.2016.11383 89

Hausmann, L. R., Myaskovsky, L., Niyonkuru, C., Oyster, M. L., Switzer, G. E., Burkitt, K. H.,
Fine, M. J., Gao, S., \& Boninger, M. L. (2015). Examining implicit bias of physicians who care for individuals with spinal cord injury: A pilot study and future directions. The Journal of Spinal Cord Medicine, 38(1), 102-110. https://doi.org/10.1179/2045772313Y.000000 0184

Hedden, B. J., Comartin, E., Hambrick, N., \& Kubiak, S. (2021). Racial disparities in access to and utilization of jail- and community-based mental health treatment in 8 US midwestern jails in 2017. American Journal of Public Health, 111(2), 277-285. https://doi.org/10.2105/AJPH.2020.305992

Hirsh, A. T., Miller, M. M., Hollingshead, N. A., Anastas, T., Carnell, S. T., Lok, B. C., Chu, C., Zhang, Y., Robinson, M. E., Kroenke, K., \& Ashburn-Nardo, L. (2019). A randomized controlled trial testing a virtual perspectivetaking intervention to reduce race and socioeconomic status disparities in pain care. Pain, 160(10), 2229-2240. https://doi.org/10.1097/j.pain.0000000000001 634

Hoffman, K. M., Trawalter, S., Axt, J. R., \& Oliver, M. N. (2016). Racial bias in pain assessment and treatment recommendations, and false beliefs about biological differences between blacks and whites. Proceedings of the National Academy of Sciences of the United States of America, 113(16), 4296-4301. https://doi.org/10.1073/pnas.1516047113

Iezzoni, Rao, S. R., Ressalam, J., Bolcic-Jankovic, D., Agaronnik, N. D., Donelan, K., Lagu, T., \& Campbell, E. G. (2021). Physicians' perceptions of people with disability and their health care. Health Affairs Web Exclusive, 40(2), 297-306. https://doi.org/10.1377/hlthaff.2020.01452

Madara, J. L. (2021, February 17). Reckoning with medicine's history of racism. American Medical Association. Retrieved October 1, 2021, from https://www.amaassn.org/about/leadership/reckoning-medicines-history-racism

Marcella, A., Garrick, O., \& Graziani, G. (2019). Does diversity matter for health? Experimental evidence from Oakland. American Economic 
Review,

109(12): https://doi.org/10.1257/aer.20181446

Mills, A. M., Shofer, F. S., Boulis, A. K., Holena, D. N., \& Abbuhl, S. B. (2011). American Journal of Emergency Medicine, 29(7), 752-756. https://doi.org/10.1016/j.ajem.2010.02.023

Mossey, J. M. (2011). Defining racial and ethnic disparities in pain management. Clinical Orthopaedics and Related Research, 469(7), 1859-1870. https://doi.org/10.1007/s11999011-1770-9

Nguyen, G. C., \& Patel, A. M. (2013). Racial disparities in mortality in patients undergoing bariatric surgery in the U.S.A. Obesity Surgery, 23(10), 1508-1514. https://doi.org/10.1007/s11695-013-0957-4

Oxford Learner's Dictionaries. (n.d.). Person-of-colour noun. Retrieved December 1, 2021, from https://www.oxfordlearnersdictionaries.com/u s/definition/english/person-of-colour

Oliver, M.N., Wells, K. M., Joy-Gaba, J. A., Hawkins, C. B., \& Nosek, B. A. (2014). Do physicians' implicit views of African Americans affect clinical decision making? Journal of the American Board of Family Medicine, 27(2), 177-188.

https://doi.org/10.3122/jabfm.2014.02.120314

Page, M.J., McKenzie, J. E., Bossuyt, P. M., Boutron, I., Hoffmann, T.C., Mulrow, C.D., Shamseer, L., Tetzlaff, J. M., Akl, E. A., Brennan, S. E., Chou, R., Glanville, J., Grimshaw, J.M. , Hróbjartsson, A., Lalu, M. M., Li, T., Loder, E. W., Mayo-Wilson, E., McDonald, S., \& Moher, D. (2021). The PRISMA 2020 statement: an updated guideline for reporting systematic reviews. BMJ (Online), 372, n71-n71. https://doi.org/10.1136/bmj.n71

Pearl, R. L., \& Percec, I. (2019). Ageism and health in patients undergoing cosmetic procedures. Aesthetic Surgery Journal, 39(7), NP288NP292. https://doi.org/10.1093/asj/sjy283

Pletcher, M. J., Kertesz, S. G., Kohn, M. A., \& Gonzales, R. (2008). Trends in opioid prescribing by race/ethnicity for patients seeking care in US emergency departments. Journal of the American Medical Association, 299(1), 70-78.
Richardson, W. S., Wilson, M. C., Nishikawa, J., \& Hayward, R. S. (1995). The well-built clinical question: a key to evidence-based decisions. ACP Journal Club, 123(3), A12-13. https://doi.org/10.7326/ACPJC-1995-123-3A12

Ross, A. B., Kalia, V., Chan, B. Y., \& Li, G. (2020). The influence of patient race on the use of diagnostic imaging in United States emergency departments: data from the National Hospital Ambulatory Medical Care survey. BMC health Services Research, 20(1), 840. https://doi.org/10.1186/s12913-020-05698-1

Staton, L. J., Panda, M., Chen, I., Genao, I., Kurz, J., Pasanen, M., Mechaber, A. J., Menon, M., O'Rorke, J., Wood, J., Rosenberg, E., Faeslis, C., Carey, T, Calleson, D., \& Cykert, S. (2007). When race matters: Disagreement in pain perception between patients and their physicians in primary care. Journal of the National Medical Association, 99(5), 532-538.

Todd, K. H., Deaton, C., D’Adamo, A.P., \& Goe, L. (2000) Ethnicity and analgesic practice. Annals of Emergency Medicine, 35(1), 11-16, https://doi.org/10.1016/S0196-644(00)700990

Todd, K. H., Ducharme, J., Choiniere, M., Cameron, S., Crandall, S., Fosnochi, D. E., Homel, P., \& Tanabe, P. (2007). Pain in the emergency department: Results of the Pain and Emergency Medicine Initiative (PEMI) multicenter study. Journal of Pain, 8(6), 460-466. https://doi.org/ 10.1016/j.jpain.2006.12.005

U.S. Census Bureau. (2021, October 8). Population Projections. Census.Gov. Retrieved November 5 , 2021, from https://www.census.gov/programssurveys/popproj.html

VanPuymbrouck, L., \& Friedman, C. (2020). Relationships between occupational therapy students' understandings of disability and disability attitudes. Scandinavian Journal of Occupational Therapy, 27(2), 122-132. https://doi.org/10.1080/11038128.2019.15963 10

VanPuymbrouck, L., Friedman, C., \& Feldner, H. (2020). Explicit and implicit disability attitudes of healthcare providers. Rehabilitation 
Psychology, 65(2), 101-112. https://doi.org/10.1037/rep0000317

Williams, D. R., \& Cooper, L. A. (2019). Reducing racial inequities in health: Using what we already know to take action. International journal of environmental research and public health, 16(4), 606.

https://doi.org/10.3390/ijerph16040606 
Appendix A: Figure 1. PRISMA flow diagram of literature search for Implicit bias against BIPOC patients in healthcare settings in the United States

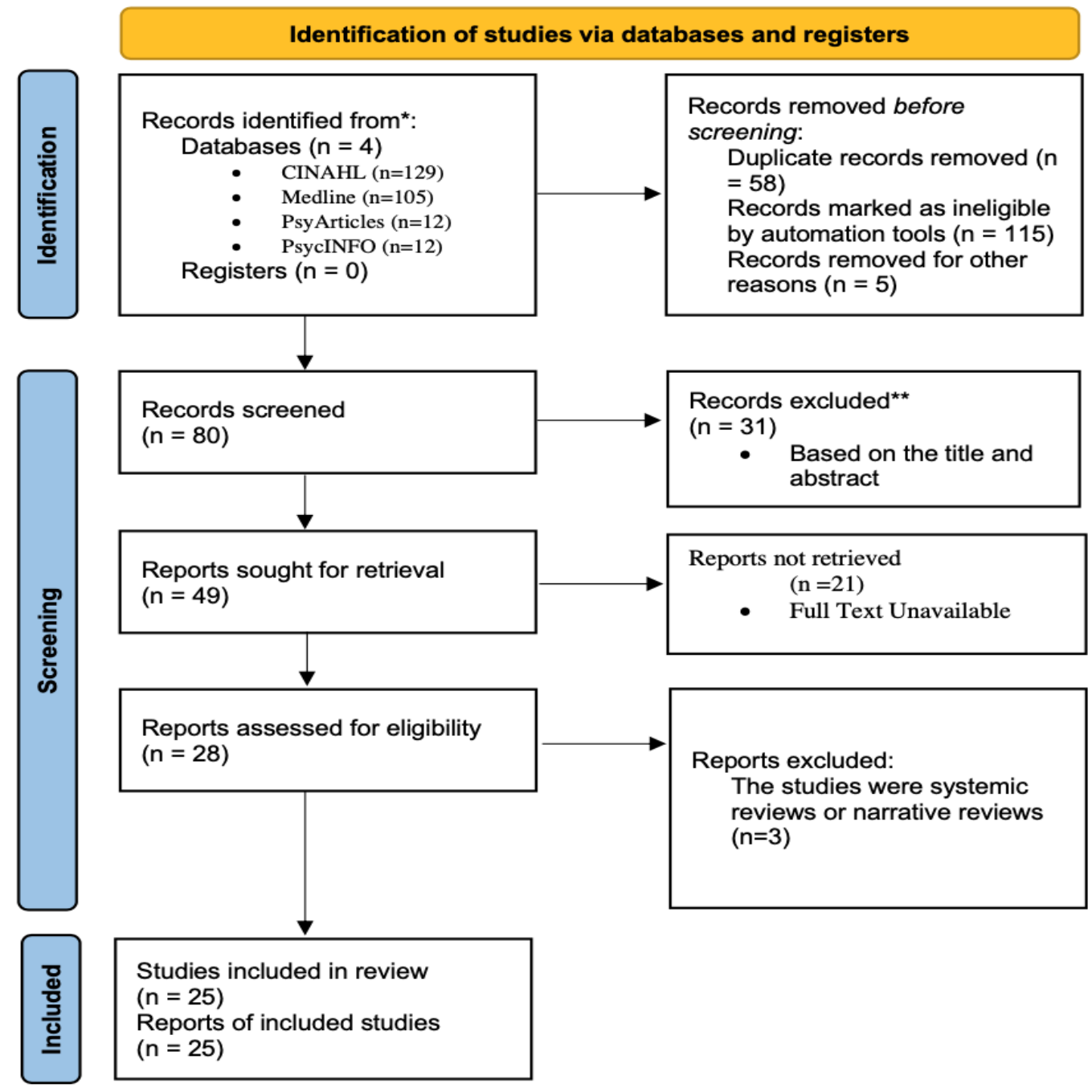

Note. Figure 1 presents the PRISMA flow diagram used to determine the flow of information for data search for implicit bias studies. The figure indicated identification, screening, eligibility, and inclusion (and exclusion) stages. 
Appendix B: Table 1. PICO Model as a Literature Search for Inclusion Criteria

\begin{tabular}{|l|l|}
\hline Table 1: PICO Inclusion Factors & \multicolumn{1}{|l|}{ Explanation } \\
\hline Population & $\begin{array}{l}\text { Black, Indigenous, People of Color patients (18+ years and older); } \\
\text { Based in the United States only }\end{array}$ \\
\hline Intervention & any BIPOC study on implicit bias (IAT, randomized, correlational, etc.) \\
\hline Comparison & no BIPOC implicit bias reported \\
\hline Outcomes & $\begin{array}{l}\text { the impact of implicit bias on BIPOC patients; } \\
\text { how it impacts overall health and level of care }\end{array}$ \\
\hline Other & $\begin{array}{l}\text { Published in a peer-reviewed academic journal in English. } \\
\text { Articles published between 2012-2021. }\end{array}$ \\
\hline
\end{tabular}

Note. Table 1 frames the research question based on the indicated population, intervention, control, and outcomes (PICO) model. 
Appendix C: Table 2. Summary of Implicit Bias BIPOC Patient Studies (2016-2021)

\begin{tabular}{|c|c|c|c|c|c|c|}
\hline $\begin{array}{l}\text { Study } \\
\text { No. }\end{array}$ & Author and Year & Study Design and Sample Size & Setting & $\begin{array}{c}\text { Bias Against } \\
\text { (target population) }\end{array}$ & $\begin{array}{c}\text { Type of } \\
\text { Implicit Bias }\end{array}$ & Outcome \\
\hline 1 & $\begin{array}{l}\text { Armstrong et al. } \\
2013\end{array}$ & $\begin{array}{l}\text { Random digit dialing survey } \\
\text { Revised Health Care System Distrust } \\
\text { (HCSD) scale } \\
\mathbf{n}=2029 \text { adults }\end{array}$ & $\begin{array}{l}40 \text { US Metropolitan } \\
\text { Statistical Areas }\end{array}$ & $\begin{array}{l}\text { African American } \\
\text { adults }\end{array}$ & Racial & $\begin{array}{l}\text { Adjusting for experiences of racial discrimination caused } \\
\text { the association distrust to be lower among African } \\
\text { Americans than Whites (OR } 0.53,95 \% \text { CI } 0.33-0.85 \text { for } \\
\text { the overall measure). }\end{array}$ \\
\hline 2 & $\begin{array}{l}\text { Badreldin et al. } \\
2019\end{array}$ & $\begin{array}{l}\text { Retrospective cohort study } \\
\mathbf{n}=9,900 \text { (postpartum women) }\end{array}$ & $\begin{array}{l}\text { Single, high-volume } \\
\text { tertiary care center }\end{array}$ & $\begin{array}{l}\text { Non-Hispanic black, } \\
\text { and Hispanic women } \\
\text { seeking postpartum } \\
\text { pain management }\end{array}$ & Racial & $\begin{array}{l}\text { Compared to non-Hispanic white women, Hispanic and } \\
\text { non-Hispanic black women had significantly greater odds } \\
\text { of reporting a pain score of } \geq 5 \text {, but received significantly } \\
\text { fewer inpatient morphine milligram equivalents/day and } \\
\text { were significantly less likely to receive an opioid } \\
\text { prescription at discharge. }\end{array}$ \\
\hline 3 & $\begin{array}{l}\text { Blair et al. } \\
2013\end{array}$ & $\begin{array}{l}\text { Telephone survey, IAT } \\
\mathbf{n}=210 \text { (PCP) } \\
\mathbf{n}=6129 \text { (patients) }\end{array}$ & $\begin{array}{l}\text { Denver Health community } \\
\text { clinics, Kaiser Permanente } \\
\text { Colorado, a non-profit health } \\
\text { maintenance organization }\end{array}$ & $\begin{array}{l}\text { Black and Latino } \\
\text { patients with } \\
\text { hypertension }\end{array}$ & $\begin{array}{l}\text { Racial } \\
\text { Ethnic }\end{array}$ & $\begin{array}{l}\text { Compared to white patients, black patients gave mostly } \\
\text { equivalent ratings to the clinicians (composite scale } \\
\text { difference, } \mathrm{P}=.84 \text { ), whereas Latino patients gave } \\
\text { comparatively lower ratings (com- posite scale difference, } \\
\mathrm{P}<.0001 \text { ). Stronger the clinicians' implicit preference for } \\
\text { white over blacks. }\end{array}$ \\
\hline 4 & $\begin{array}{l}\text { Blair et al. } \\
2014\end{array}$ & $\begin{array}{l}\text { IAT } \\
\mathrm{n}=138 \text { (PCC) } \\
\mathrm{N}=\mathbf{4 7 9 4} \text { (patients) }\end{array}$ & Primary care setting & $\begin{array}{l}\text { Black and Latino } \\
\text { patients with } \\
\text { hypertension }\end{array}$ & $\begin{array}{l}\text { Racial } \\
\text { Ethnic }\end{array}$ & $\begin{array}{l}\text { Differences in treatment intensification, medication adherence } \\
\text { and hypertension control were unrelated to clinician implicit } \\
\text { bias for black patients }(P=0.85, P=0.06 \text { and } P=0.31 \text {, } \\
\text { respectively) and for Latino patients ( } P=0.55, P=0.40 \text { and } \\
P=0.79 \text {, respectively). An increase in clinician bias from } \\
\text { average to strong was associated with a relative change of } \\
\text { less than } 5 \% \text { in all outcomes for black and Latino patients. }\end{array}$ \\
\hline 5 & $\begin{array}{l}\text { Breathett et al. } \\
2020\end{array}$ & $\begin{array}{l}\text { Interview } \\
\text { Clinical vignettes } \\
\text { Thematic analysis } \\
\mathbf{n}=46 \text { (clinicians) }\end{array}$ & $\begin{array}{l}\text { International heart transplant } \\
\text { conference }\end{array}$ & $\begin{array}{l}\text { African-American } \\
\text { women receiving } \\
\text { advanced heart failure } \\
\text { therapies }\end{array}$ & $\begin{array}{l}\text { Gender } \\
\text { Racial }\end{array}$ & $\begin{array}{l}\text { Clinicians critiqued the appearance of women more } \\
\text { harshly than men. There was more concern regarding } \\
\text { appropriateness of prior care of the African-American } \\
\text { woman compared to the White woman and greater } \\
\text { concerns about adequacy of social support of the women. }\end{array}$ \\
\hline 6 & $\begin{array}{l}\text { Campesino et al. } \\
2012\end{array}$ & $\begin{array}{l}\text { Mixed methods } \\
\mathbf{n}=39 \text { (patients) }\end{array}$ & $\begin{array}{l}\text { Participants' homes in the } \\
\text { metropolitan areas of Phoenix } \\
\text { and Tucson, AZ }\end{array}$ & $\begin{array}{l}\text { Latinas and African } \\
\text { American women with } \\
\text { breast cancer }\end{array}$ & $\begin{array}{l}\text { Racial } \\
\text { Ethnic } \\
\text { Socioeconomic } \\
\text { class }\end{array}$ & $\begin{array}{l}46 \% \text { of women believed race and spoken language } \\
\text { affected the quality of health care. Perceived disrespect } \\
\text { from providers was attributed to participant's skin color, } \\
\text { income level, citizenship status, and English proficiency. }\end{array}$ \\
\hline 7 & $\begin{array}{l}\text { Cooper et al. } \\
2012\end{array}$ & $\begin{array}{l}\text { Cross sectional study } \\
\text { IAT } \\
\mathbf{n}=269 \text { (patients) } \\
\mathbf{n}=40 \text { (PCC) }\end{array}$ & $\begin{array}{l}\text { United States } \\
\text { Urban community-based } \\
\text { practices }\end{array}$ & Black patients & Racial bias & $\begin{array}{l}\text { General race bias was associated with more clinician verbal } \\
\text { dominance, lower patient positive affect, and poorer ratings } \\
\text { of interpersonal care. Race and compliance stereotyping } \\
\text { was associated with longer visits, slower speech, less } \\
\text { patient centeredness, and poorer ratings of interpersonal care. }\end{array}$ \\
\hline 8 & $\begin{array}{l}\text { Daugherty et al. } \\
2017\end{array}$ & $\begin{array}{l}\text { Between-subjects randomized } \\
\text { experimental design } \\
\text { Web-based survey, IAT } \\
\text { Clinical vignette } \\
\mathbf{n}=503 \text { (cardiologists) }\end{array}$ & United States & $\begin{array}{l}\text { Female patients } \\
\text { suspected for coronary } \\
\text { artery disease }\end{array}$ & Gender & $\begin{array}{l}\text { Cardiologists were less likely to rate angiography as highly } \\
\text { useful for a female patient compared with a male patient. }\end{array}$ \\
\hline 9 & $\begin{array}{l}\text { Edmonds et al. } \\
2017\end{array}$ & $\begin{array}{l}\text { Self-administered survey } \\
\text { Case vignette } \\
\mathrm{n}=76(\mathrm{OB} / \mathrm{GYN}) \\
\mathrm{n}=1 \text { (nurse practitioners) }\end{array}$ & Clinical conference & $\begin{array}{l}\text { Pregnant Black women } \\
\text { receiving chronic pain } \\
\text { management }\end{array}$ & Racial & $\begin{array}{l}\text { GYN are more likely to conduct urine drug tests on white } \\
\text { than black patients ( } \mathrm{P}=0.008) \text { and more likely to suspect that } \\
\text { white patients would divert the medication }(\mathrm{P}=50.021) \text {. For } \\
\text { the white patient, providers were primarily concerned about } \\
\text { the risk of abuse or addiction, whereas, for the black patient, } \\
\text { the primary concern was harm to the fetus. }\end{array}$ \\
\hline 10 & $\begin{array}{l}\text { Eliacin et al. } \\
2020\end{array}$ & $\begin{array}{l}\text { Interview } \\
\mathrm{n}=85 \text { (patients) }\end{array}$ & $\begin{array}{l}\text { Mental health services from } \\
\text { the US Department of } \\
\text { Veterans Affairs }\end{array}$ & $\begin{array}{l}\text { African-American } \\
\text { veterans }\end{array}$ & $\begin{array}{l}\text { Racial } \\
\text { Veteran }\end{array}$ & $\begin{array}{l}\text { Several identity threatening cues that include lack of racial } \\
\text { diversity representation in healthcare settings, and } \\
\text { perceptions of providers' fears of Black patients. } 26 \% \text { of } \\
\text { participants explicitly stated that race plays a role in } \\
\text { healthcare. }\end{array}$ \\
\hline 11 & Fisch et al. 2012 & $\begin{array}{l}\text { Prospective study } \\
\mathrm{n}=3,023 \text { (ambulatory patients) }\end{array}$ & Medical oncology outpatients & $\begin{array}{l}\text { BIPOC patients with } \\
\text { breast, prostate, colon } \\
\text { /rectum, or lung cancer } \\
\text { seeking pain } \\
\text { management }\end{array}$ & $\begin{array}{l}\text { Racial } \\
\text { Ethnic }\end{array}$ & $\begin{array}{l}\text { The odds of a non-Hispanic white patient having inadequate } \\
\text { pain treatment at both the initial assessment and follow-up } \\
\text { were approximately half those of a minority patient after } \\
\text { adjusting for other explanatory variables } \\
(\mathrm{OR}, 0.51 ; 95 \% \mathrm{CI}, 0.37 \text { to } 0.70 ; \mathrm{P}=.002)\end{array}$ \\
\hline 12 & $\begin{array}{l}\text { Freeman et al. } \\
2017\end{array}$ & $\begin{array}{l}\text { Semistructured interviews } \\
\mathrm{n}=37 \text { (patients) }\end{array}$ & New York City & $\begin{array}{l}\text { African American/ } \\
\text { Black and Hispanic } \\
\text { persons with HIV }\end{array}$ & $\begin{array}{l}\text { Racial } \\
\text { Socioeconomic } \\
\text { class }\end{array}$ & $\begin{array}{l}\text { 1) via the extent to which healthcare settings were } \\
\text { experienced as overly institutionalized and, dehumanizing } \\
\text { 2) distrust of medical institutions and healthcare providers, } \\
\text { which led AABH-PLWH to feel pressured to take HIV } \\
\text { antiretroviral therapy when it was offered } \\
\text { 3) perceptions that patients are excluded from the } \\
\text { health decision-making process; } \\
\text { 4) an over-emphasis on antiretroviral therapy compared to } \\
\text { other non-HIV related priorities. }\end{array}$ \\
\hline 13 & $\begin{array}{l}\text { Hagiwara et al. } \\
2017\end{array}$ & $\begin{array}{l}\text { Secondary data analysis } \\
\mathrm{n}=14 \text { (physicians) } \\
\mathrm{n}=117 \text { (patients) }\end{array}$ & $\begin{array}{l}\text { Primary clinics in the U.S. } \\
\text { that serve low-income, } \\
\text { residentially segregated } \\
\text { minority patient populations. }\end{array}$ & Black patients & Racial & $\begin{array}{l}\text { Non-Black physicians with higher levels of implicit, but not } \\
\text { explicit, racial bias had larger physician-patient talk time } \\
\text { ratios. Black patients with higher levels of perceived } \\
\text { discrimination had smaller physician-patient talk time ratios. } \\
\text { smaller physician-patient talk time ratios were associated } \\
\text { with less patient subsequent adherence. }\end{array}$ \\
\hline 14 & $\begin{array}{l}\text { Haider et al. } \\
2015\end{array}$ & $\begin{array}{l}\text { Web-based survey } \\
\mathrm{n}=230 \text { (physicians) }\end{array}$ & $\begin{array}{l}\text { Surgery and related specialties } \\
\text { at an academic, level I trauma } \\
\text { center }\end{array}$ & Patients & $\begin{array}{l}\text { Racial } \\
\text { Socioeconomic } \\
\text { class }\end{array}$ & $\begin{array}{l}\text { Implicit race and social class biases were present in most } \\
\text { respondents. Women demonstrated less bias concerning race } \\
\text { and social class. Race and class scores were similar across } \\
\text { departments (general surgery, orthopedics, urology, etc), } \\
\text { race, or age. }\end{array}$ \\
\hline 15 & $\begin{array}{l}\text { Hausmann et al. } \\
2015\end{array}$ & $\begin{array}{l}\text { Pilot study } \\
\text { Cross-sectional surveys } \\
\mathrm{n}=162 \text { (patients) } \\
\mathrm{n}=14 \text { (physicians) }\end{array}$ & $\begin{array}{l}\text { Four national SCI Model } \\
\text { Systems sites }\end{array}$ & $\begin{array}{l}\text { Black patients with } \\
\text { spinal cord injury }\end{array}$ & $\begin{array}{l}\text { Racial } \\
\text { Disability }\end{array}$ & $\begin{array}{l}\text { Physicians had a mean bias score of } 0.62(\mathrm{SD}=0.35) \text {, } \\
\text { indicating a strong pro-white/anti-black bias. Greater } \\
\text { physician bias was associated with disability among } \\
\text { individuals with SCI. }\end{array}$ \\
\hline 16 & $\begin{array}{l}\text { Hedden et al. } \\
2021\end{array}$ & $\begin{array}{l}\text { Cohort study } \\
\mathrm{n}=623 \text { (patients) }\end{array}$ & 8 Midwestern Jails in the US. & $\begin{array}{l}\text { Black patients in jail } \\
\text { with mental health } \\
\text { issues }\end{array}$ & Racial & $\begin{array}{l}\text { Compared with PoC, White people had } 1.9 \text { times greater odds } \\
\text { of receiving community-based mental health and substance } \\
\text { use treatment and } 4.5 \text { times greater odds of receiving } \\
\text { co-occurring disorder treatment. }\end{array}$ \\
\hline
\end{tabular}




\begin{tabular}{|c|c|c|c|c|c|c|}
\hline 17 & 7 Hirsh et al. 2019 & $\begin{array}{l}\text { Randomized Control Trial } \\
\mathrm{n}=436 \text { (Physician residents and } \\
\text { fellows) }\end{array}$ & Indiana University & $\begin{array}{l}\text { Black patients with } \\
\text { chronic pain }\end{array}$ & Racial & $\begin{array}{l}\text { Levels of implicit bias varied among clinicians, and those } \\
\text { with greater implicit bias were rated lower in patient-centered } \\
\text { care by their black patients as compared with a reference } \\
\text { group of white patients }(\mathrm{P}=.04) \text {. Latino patients gave the } \\
\text { clinicians lower ratings than did other groups }(\mathrm{P}<.0001), \\
\text { and this did not depend on the clinicians' implicit bias } \\
(\mathrm{P}=.98) \text {. }\end{array}$ \\
\hline 18 & $\begin{array}{l}\text { Hoffman et al. } \\
2016\end{array}$ & $\begin{array}{l}\text { Mixed Methods } \\
\text { Study } 1: \mathrm{n}=92 \text { (white individuals } \\
\text { without medical training) } \\
\text { Study } 2: \mathrm{n}=222 \text { (medical students } \\
\text { and residents) }\end{array}$ & $\begin{array}{l}\text { Study } 1 \text { - Amazon's } \\
\text { Mechanical Turk } \\
\text { Study } 2 \text { - Large public } \\
\text { university and multiple } \\
\text { resident sites }\end{array}$ & $\begin{array}{l}\text { Black Americans } \\
\text { seeking pain } \\
\text { management }\end{array}$ & Racial & $\begin{array}{l}\text { Participants who endorsed false beliefs about biological } \\
\text { differences between blacks and whites rated the black (vs. } \\
\text { white) patient's pain as lower and made less accurate } \\
\text { treatment recommendations. }\end{array}$ \\
\hline 19 & $\begin{array}{l}\text { Nguyen \& Patel } \\
2013\end{array}$ & $\begin{array}{l}\text { Secondary data analysis } \\
\mathrm{n}=115,507 \text { (patients) }\end{array}$ & $\begin{array}{l}\text { In-hospital, perioperative } \\
\text { setting }\end{array}$ & $\begin{array}{l}\text { Non-Hispanic blacks } \\
\text { undergoing bariatric } \\
\text { surgery }\end{array}$ & $\begin{array}{l}\text { Racial } \\
\text { Socioeconomic } \\
\text { class }\end{array}$ & $\begin{array}{l}\text { Mortality rate was } 2.5 \text { deaths per } 1,000 \text { and was higher } \\
\text { among non-Hispanic blacks compared to non-Hispanic } \\
\text { whites ( } 3.7 \text { vs. } 2.3 \text { per } 1,000 ; \mathrm{P}=0.007) \text {. Racial mortality } \\
\text { disparities were most pronounced among males and at } \\
\text { hospitals with lowest surgical volumes. }\end{array}$ \\
\hline 20 & Oliver et al. 2014 & $\begin{array}{l}\text { Web-based survey } \\
\mathrm{n}=543 \text { (family and internal medicine } \\
\text { physicians) }\end{array}$ & United States & $\begin{array}{l}\text { Black patients with } \\
\text { osteoarthritis }\end{array}$ & Racial & $\begin{array}{l}\text { 1. Subjects displayed a strong implicit preference for whites } \\
\text { over blacks }(\mathrm{P}<.0001) \text { and associated "medically } \\
\text { cooperative" with whites over blacks }(\mathrm{P}<.0001) \text {. } \\
\text { 2. Physicians reported significantly greater liking for whites } \\
\text { over blacks }(\mathrm{P}<.0001) \text { and reported believing whites were } \\
\text { more medically cooperative than blacks }(\mathrm{P}<.0001) \text {. } \\
\text { 3. Participants reported providing similar care for white and } \\
\text { black patients }(\mathrm{P}=.10) \text { but agreed that subconscious biases } \\
\text { could influence their treatment decisions }(\mathrm{P}<.0001) \text {. }\end{array}$ \\
\hline 21 & $\begin{array}{l}\text { Pearl \& Percec } \\
2018\end{array}$ & $\begin{array}{l}\text { Brief questionnaire } \\
\mathrm{n}=50 \text { (patients) }\end{array}$ & $\begin{array}{l}\text { University-based, single- } \\
\text { surgeon, aesthetic plastic } \\
\text { surgery clinic }\end{array}$ & $\begin{array}{l}\text { Patients seeking } \\
\text { cosmetic procedures }\end{array}$ & Age & $\begin{array}{l}36 \% \text { of patients reported feeling excluded by friends/family/ } \\
\text { coworkers, being teased or mocked, or having negative } \\
\text { assumptions made by others about them due to age. }\end{array}$ \\
\hline 22 & $\begin{array}{l}\text { Ross et al. } \\
2020\end{array}$ & $\begin{array}{l}\text { Secondary data analysis } \\
\mathrm{n}=131,558,553 \text { (patient encounters } \\
\text { each year for } 11 \text { years) }\end{array}$ & $\begin{array}{l}\text { Urban and non-urban hospital } \\
\text { setting - emergency } \\
\text { department }\end{array}$ & $\begin{array}{l}\text { Non-white patients } \\
\text { receiving medical } \\
\text { imaging }\end{array}$ & $\begin{array}{l}\text { Racial } \\
\text { Ethnic } \\
\text { Age } \\
\text { Gender }\end{array}$ & $\begin{array}{l}\text { More than } 30 \% \text { of participants reported age as the main } \\
\text { reason for everyday discrimination. Participants who reported } \\
\text { experiencing age-based discrimination, compared with those } \\
\text { who did not, had worse self-rated health, lower self-esteem, } \\
\text { and greater anticipated age-based discrimination. }\end{array}$ \\
\hline 23 & $\begin{array}{l}\text { VanPuymbrouck } \\
\text { et al. } 2020\end{array}$ & $\begin{array}{l}\text { Secondary data analysis } \\
\text { IAT on disability attitudes } \\
\mathrm{n}=25,006 \text { (healthcare providers) }\end{array}$ & United States & Patients with disability & Disability & $\begin{array}{l}\text { Implicit attitudes }(\mathrm{M}=0.54) \text { revealed they moderately } \\
\text { preferred nondisabled people - they were aversive ableists. } \\
\text { Age, gender, political orientation, and having relationships } \\
\text { with friends, family, and being a person with disability. }\end{array}$ \\
\hline 24 & $\begin{array}{l}\text { VanPuymbrouck \& } \\
\text { Friedman } 2020\end{array}$ & $\begin{array}{l}\text { Mixed methods } \\
\text { IAT } \\
\mathrm{n}=67 \text { (Occupational therapy students) }\end{array}$ & $\begin{array}{l}3 \text { universities of a large urban } \\
\text { setting within the U.S. }\end{array}$ & Patients with disability & Disability & $\begin{array}{l}\text { Students enter curriculums with vast differences in } \\
\text { understandings of people with disabilities and these may } \\
\text { provide a basis for and contribute to differences in attitudes } \\
\text { of disability. }\end{array}$ \\
\hline 25 & $\begin{array}{l}\text { Zhang et al. } \\
2020\end{array}$ & $\begin{array}{l}\text { Cross-sectional study } \\
\text { Secondary data analysis } \\
\mathrm{n}=247,989 \text { (patients) }\end{array}$ & Emergency department & BIPOC patients & $\begin{array}{l}\text { Racial } \\
\text { Ethnic }\end{array}$ & $\begin{array}{l}\text { Black patients were } 10 \% \text { less likely than White patients to be } \\
\text { admitted to the hospital and were } 1.26 \text { times more likely than } \\
\text { White patients to die in the ED or hospital. }\end{array}$ \\
\hline
\end{tabular}

Note. Table 2 summarizes the implicit bias studies based on study design, sample size, setting, target population, type of implicit bias, and outcomes. 